Research Article

\title{
Magnetorheological Elastomer Precision Platform Control Using OFFO-PID Algorithm
}

\author{
Ying-Qing Guo $\mathbb{D}^{1},{ }^{1}$ Jie Zhang, ${ }^{1}$ Dong-Qing $\mathrm{He}^{1}$ and Jin-Bao $\mathrm{Li}^{2}$ \\ ${ }^{1}$ Mechanical and Electronic Engineering College, Nanjing Forestry University, Nanjing 210037, China \\ ${ }^{2}$ Jiangsu Southeast Special Engineering \& Technology Co., Ltd, Nanjing 210008, China \\ Correspondence should be addressed to Ying-Qing Guo; gyingqing@126.com
}

Received 7 November 2019; Revised 16 January 2020; Accepted 31 January 2020; Published 26 February 2020

Academic Editor: Sakar Mohan

Copyright (C) 2020 Ying-Qing Guo et al. This is an open access article distributed under the Creative Commons Attribution License, which permits unrestricted use, distribution, and reproduction in any medium, provided the original work is properly cited.

\begin{abstract}
The magnetorheological elastomer (MRE) is a kind of smart material, which is often processed as vibration isolation and mitigation devices to realize the vibration control of the controlled system. The key to the effective isolation of vibration and shock absorption is how to accurately and in real time determine the magnitude of the applied magnetic field according to the motion state of the controlled system. In this paper, an optimal fuzzy fractional-order PID (OFFO-PID) algorithm is proposed to realize the vibration isolation and mitigation control of the precision platform with MRE devices. In the algorithm, the particle swarm optimization algorithm is used to optimize initial values of the fractional-order PID controller, and the fuzzy algorithm is used to update parameters of the fractional-order PID controller in real time, and the fractional-order PID controller is used to produce the control currents of the MRE devices. Numerical analysis for a platform with the MRE device is carried out to validate the effectiveness of the algorithm. Results show that the OFFO-PID algorithm can effectively reduce the dynamic responses of the precision platform system. Also, compared with the fuzzy fractional-order PID algorithm and the traditional PID algorithm, the OFFO-PID algorithm is better.
\end{abstract}

\section{Introduction}

The precision platform is the carrier of precision instrument work. The external excitation such as environmental vibration affects the performance of the precision instrument to a great extent, even affects its service life and the normal work of operators. Many researchers adopted the passive control method to mitigate the vibration of the platform due to its economic efficiency and convenience [1]. In this paper, the semiactive control method of the magnetorheological elastomer (MRE) device is used to realize the vibration control of the precision platform.

The MRE is made of polymer and micron-sized soft magnetic materials. After solidification, the mechanical, electrical, and magnetic properties of the MRE will change with the change of the external magnetic field. Therefore, it belongs to a branch of MR materials. The MRE has the advantages of both MR material and elastomer, and it avoids the problem of easy settlement of MR fluid. That is to say, it retains the controllable properties of the MR material's stiffness and damping, that is, its elasticity, shear storage modulus, and loss factor are controllable, and it overcomes the shortcomings of the MR fluid such as poor sedimentation and stability [2-5]. MREs can be used to make various shock absorber devices or vibration isolation and mitigation devices, such as shock absorber, suspension, engine frame, axle lining, shock vibration absorber, shock absorber, and base isolator [6-10].

The system equipped with MR devices has strong nonlinearity and is time varying. If the MR devices are expected to have an effective vibration isolation and mitigation effect for the system, the key is to have appropriate control current (or control voltage) for MR devices. Many control algorithms on systems incorporated with MR devices have been proposed. In 1996, Dyke et al. proposed a clipped-optimal control strategy based on acceleration 
feedback for controlling MR dampers to reduce structural responses due to seismic loads. And a numerical example was given to illustrate the effectiveness of the control strategy [11]. In 2001, Schurter and Roschke used ANFIS (adaptive neuro-fuzzy inference system) to create a fuzzy controller based on acceleration of the building feedback to achieve the vibration mitigation [12]. In 2003, Xu et al. applied neural network technology to achieve semiactive control of structures with MR dampers [13]. In 2005, Wang and Liao presented an inverse neural network model for MR dampers to generate the control voltage when the MR damper is operating in a semiactive mode [14]. In 2008, Guo et al. proposed a fuzzy control strategy based on a neural network forecasting model of the building structure with MR dampers, in which a neural network forecasting model was developed to predict dynamic responses of the system with MR dampers, and a fuzzy controller is then designed to determine control currents of MR dampers [15]. In 2010, Wilson and Abdullah proposed a self-tuning fuzzy controller to regulate MR dampers' properties and reduce structural responses of single degree-of-freedom seismically excited structures [16]. In 2015, Yu et al. presented a hybrid support vector regression-based model to predict the inherent hysteresis behaviors of the MRE-based isolator and also proposed a hybrid modeling method to characterize the nonlinear dynamics of MRE isolators [17, 18]. In 2016, different control algorithms, such as the fruit fly optimization algorithm (FFOA), are employed for model parameter identification using testing data of shear force, displacement, and velocity obtained from different loading conditions [19]. In 2017, Gu et al. developed an inverse model for MRE base isolator based on the optimal general regression neural network (GRNN) and used the LQR controller and the GRNN inverse model to carry out the numerical and experimental validation of a real-time semiactive controlled MRE [20]. In 2018, Yu et al. developed a novel nonparametric model based on the artificial neural network to describe the nonlinear characteristic of the MRE base isolator. Also, in this work, a novel binary-coded cat swarm optimization algorithm (BCDCSO) was proposed to optimize the input subsets of the ELM (extreme learning machine) [21]. Leng et al. proposed an artificial neutral network approach optimized by the fuzzy algorithm (ANNOFA) system for approximately capturing the nonlinear functional relationship between inputs (displacement, frequency, and current) and output (force) of the MRE isolator [22]. In 2019, to overcome the inherent nonlinearity and hysteresis of the MRE isolator, $\mathrm{Gu}$ et al. developed a radial basis function neural network-based fuzzy logic control algorithm due to its inherent robustness and capability in coping with uncertainties [23].

In this paper, an optimization fuzzy fractional-order PID control algorithm (OFFO-PID) is proposed to control the isolation and vibration reduction system of the precision platform based on MRE, and the algorithm is composed of the fuzzy control algorithm and the fractional PID algorithm based on particle swarm optimization (PSO), which significantly improve the control accuracy of the system. In addition, using SIMULINK simulation platform, the mathematical model of the precise platform structure and the OFFO-PID control algorithm were simulated and analyzed. The simulation results of OFFO-PID are compared with the simulation results of unoptimized fuzzy fractional PID, no control condition, and traditional PID. The analysis results show that the OFFO-PID can effectively suppress the vibration response of the precision platform under certain vibration disturbance, and the simulation results show that it is obviously superior to the no control condition, unoptimized condition, and traditional PID control.

\section{Mathematical Model of the Controlled System}

2.1. Mathematical Model of the Precision Platform Structure. The precision platform discussed in this paper is the carrier of high-precision equipment operation, which is used to isolate or reduce the impact of external vibration on equipment operation. In order to isolate or reduce the influence of external vibration more effectively and make the high-precision equipment run better, MRE devices are installed between the installation base and the legs of the precision platform, as shown in Figure 1. The MRE in the device is silicone rubber-based and anisotropic. Its ferromagnetic particle volume fraction is 0.38 . Considering that the vertical movement of the platform cannot be too large, the device is provided with a limit device, and the limit displacement is not more than $1 \mathrm{~mm}$. The maximum output of the MRE isolation layer is $5708 \mathrm{~N}$. The precision platform is assumed to be square and axisymmetric. For simplifying the calculation, the entire precision platform structure is simplified to a single degree-of-freedom structure, and its mathematical model is shown in Figure 2. The vertical acceleration signals are as the external vibration interference excitation. The dynamic equation of the single degree-offreedom model for the precision platform with the MRE devices is

$$
m \ddot{z}+4 c_{0} \dot{z}+4\left(k_{0}+k_{m}\right) z=-m \ddot{z}_{g}
$$

where $m$ is the effective load mass of the precision platform; $k_{0}$ is the inherent stiffness of the MRE device; $k_{m}$ is the adjustable stiffness of the MRE device; $c_{0}$ is the inherent damping of the MRE device; $z, \dot{z}$, and $\ddot{z}$ are the vertical displacement, the vertical velocity, and the vertical acceleration of the precision platform countertop, respectively; and $\ddot{z}_{g}$ is the vertical acceleration excitation.

\subsection{Adjustable Stiffness Model of the MRE Device.} According to equation (1), it can be seen that the responses of the precision platform are affected by the adjustable stiffness of the MRE device. That means responses of the precision platform can be controlled by adjusting the adjustable stiffness of the MRE device. The adjustable stiffness $k_{m}$ is [24]

$$
k_{m}=\frac{\Delta G_{m} \cdot A}{t_{k}},
$$

where $A$ is the shear area, $t_{k}$ is the thickness of the vibration isolation and mitigation layer of MRE, and $\Delta G_{m}$ is the 


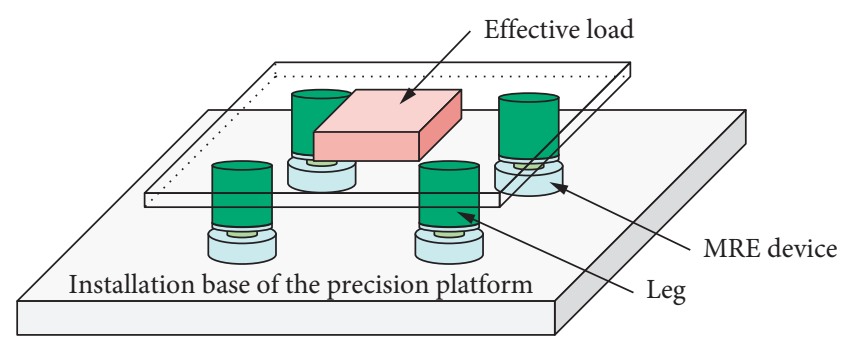

FIGURE 1: The precision platform with MRE devices.

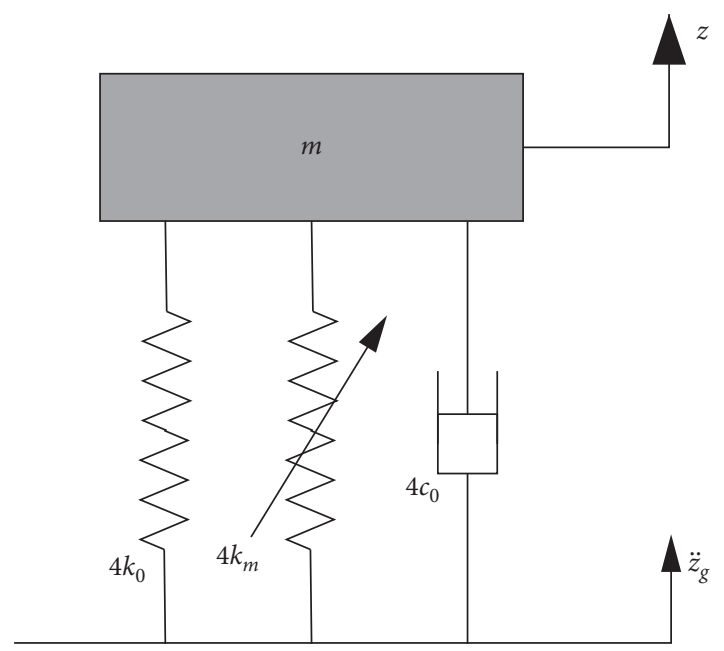

Figure 2: The single degree-of-freedom model of the precision platform with MRE devices.

magnetic-induced shear stiffness, which can be obtained through the dipole model $[3,4]$ :

$$
\Delta G_{m}=36 \phi \mu_{f} \mu_{0} \beta^{2} H_{0}^{2}\left(\frac{R}{d}\right)^{3} \xi
$$

where $\phi$ is the volume fraction of ferromagnetic particles; $\mu_{f}$ is the relative magnetic permeability of the matrix material of the MRE device; $\mu_{0}=4 \pi \times 10^{-7} \mathrm{~N} / \mathrm{A}^{2}$ is the magnetic permeability in vacuum; $H_{0}$ is the strength of the external magnetic field; $R$ is the average radius of ferromagnetic particles; $d$ is the average spacing between particles; and $\xi=\sum_{n=1}^{\infty} 1 / n^{3} \approx 1.202, \beta \approx 1$.

From equation (3), it can be seen that $\Delta G_{m}$ can be adjusted by changing the intensity of the external magnetic field. And the intensity of the external magnetic field can be adjusted by changing the control currents. That means $\Delta G_{m}$ is the function of the control current. In this paper, the MRE devices used in the precision platform were developed by $\mathrm{Xu}$ of the same research group [4]. According to the MRE device and the analysis of its magnetic circuit $[25,26]$, the $N / L_{\mathrm{e}}$ ratio is 27900 ( $N$ is the number of turns of the coil in the device, and $L_{\mathrm{e}}$ is the effective magnetic circuit length). According to the formula of magnetic field strength, $H_{0}=I_{c} N / L_{\mathrm{e}}$. So, the functional relationship between $\Delta G_{m}$ and the control current $I_{c}$ can be obtained as

$$
\Delta G_{m}=2.78 \phi \mu_{f} \mu_{0} \beta^{2} I_{c}^{2}\left(\frac{R}{d}\right)^{3} \xi \times 10^{10} .
$$

\section{Optimal Fuzzy Fractional-Order PID Control Algorithm}

3.1. The Fractional-Order PID Controller. The theory of the fractional-order PID controller was originally proposed by Podlubny [27], and its general expression is $\mathrm{PI}^{\lambda} D^{\mu}$. Compared with the traditional integer-order PID, it includes an integral order $\lambda$ and a derivative order $\mu$. Its transfer function is

$$
G_{c}(s)=k_{\mathrm{p}}+k_{\mathrm{i}} s^{-\lambda}+k_{\mathrm{d}} s^{\mu}(0<\lambda, \mu<1),
$$

where $k_{\mathrm{p}}, k_{\mathrm{i}}$, and $k_{\mathrm{d}}$ represent the proportional gain, integral gain, and differential gain, respectively. The fractional differential operators in equation (5) can be obtained by the improved Oustaloup algorithm [28]. The fractional differential operator is

$$
s^{\alpha} \approx\left(\frac{d \omega_{h}}{b}\right)\left(\frac{d s^{2}+d \omega_{h} s}{d(1-\alpha) s^{2}+b \omega_{h} s+d \alpha}\right) \prod_{k=-N}^{N} \frac{s+\omega_{k}^{\prime}}{s+\omega_{k}},
$$

where $0<\alpha<1, b>0$, and $d>0, \omega_{k}=\left(b \omega_{h} / d\right)^{(\alpha+2 k) /(2 N+1)}$, and $\omega_{k}^{\prime}=\left(d \omega_{b} / b\right)^{\alpha-2 k / 2 N-1}$.

3.2. Optimization of Fractional-Order PID Parameters. According to equation (5), there are five parameters $\left(\lambda, \mu, k_{\mathrm{p}}\right.$, $k_{\mathrm{i}}$, and $\left.k_{\mathrm{d}}\right)$ in the fractional-order PID controller that need to be determined. In this paper, the particle swarm optimization (PSO) algorithm is used to determine the optimal initial values of these five parameters. In the paper, a linearly decreasing inertial weight (LPSO) is considered instead of nonlinear ones (NPSO) mainly because the NPSO has fast convergence speed and high accuracy when optimizing lowdimensional functions, while its accuracy is far less than the LPSO when optimizing high-dimensional functions. The system function in this paper is not a low-dimensional function. In order to improve the control accuracy of the system, LPSO is selected. The evolution equation of the PSO algorithm can be described as [29]

$$
\begin{aligned}
\omega & =\omega_{\max }-(\text { iter/MaxIter }) *\left(\omega_{\max }-\omega_{\min }\right), \\
v_{t+1} & =\omega v_{t}+c_{1} r_{1}\left(P_{t}-x_{t}\right)+c_{2} r_{2}\left(G_{t}-x_{t}\right), \\
x_{t+1} & =x_{t}+v_{t+1},
\end{aligned}
$$

where $\omega$ is the inertia factor, $\omega_{\max }$ and $\omega_{\min }$ are the maximum and minimum values of the inertia factor; $x$ is the position of the particle; $v$ is the velocity of the particle; iter is the number of iterations; MaxIter is the maximum number of iterations; $c_{1}$ and $c_{2}$ are the acceleration constants; $r_{1}$ and $r_{2}$ are the random numbers in the interval $[0,1] ; P_{t}$ is the optimal position that the particle has searched so far; and $G_{t}$ is the best position that the whole particle swarm has searched so far.

In the parameter optimization process, the fitness function (also called the objective function) uses the ITAE performance indicator function [30]: 


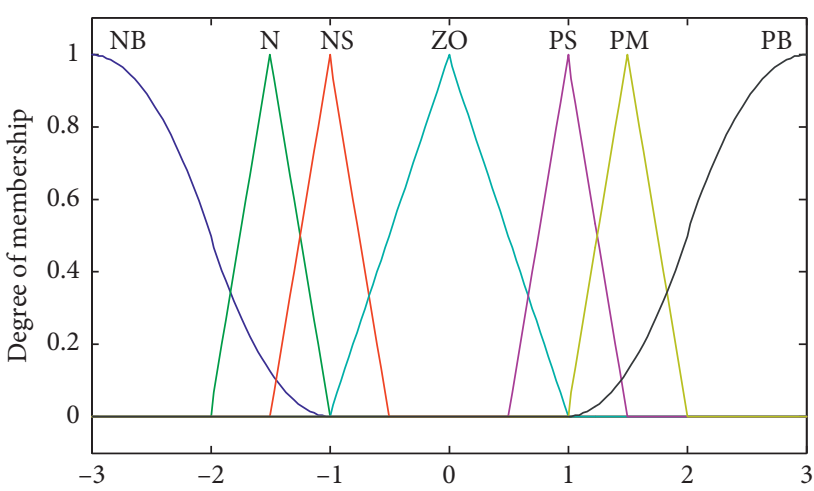

(a)

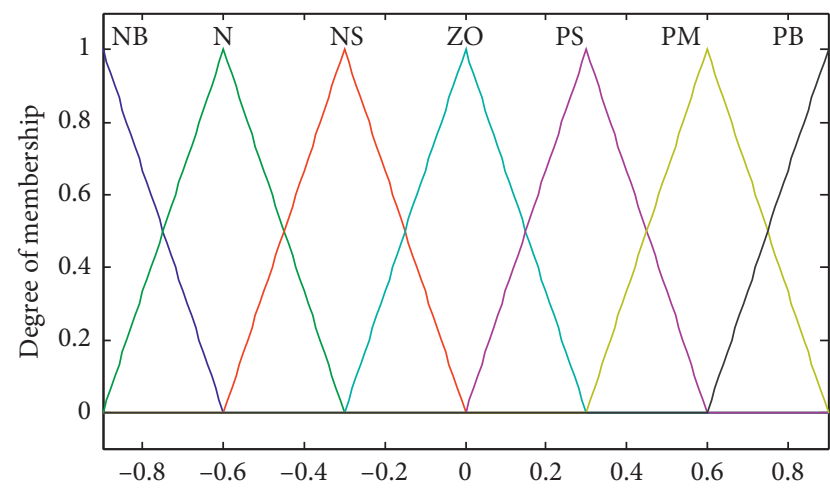

(b)

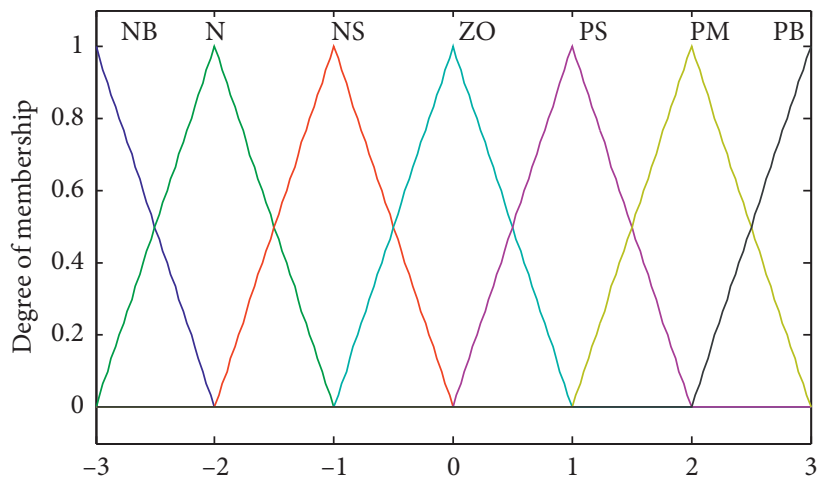

(c)

Figure 3: Membership function curves of the input and output variables of the fuzzy controller. (a) $A$ and $A C$. (b) $\Delta_{\lambda}$ and $\Delta_{\mu}$. (c) $\Delta k_{\mathrm{p}}, \Delta k_{\mathrm{i}}$, and $\Delta k_{\mathrm{d}}$.

$$
J=\int_{0}^{\infty} t|e(t)| \mathrm{d} t
$$

3.3. Design of the Fuzzy Controller. The vibration isolation and mitigation control system of the precision platform with the MRE device is a dynamic system with real-time changes in parameters, but the PSO algorithm is only used to optimize the initial values of the five parameters of the fractional-order PID controller, and it cannot adjust the five parameters in real time. The fuzzy control algorithm is a control method based on heuristic knowledge and language decision rules. It is beneficial to simulate the process and method of manual control and improve the adaptability of the control system. At the same time, the fuzzy control system has strong robustness, and the influence of disturbance and parameter variation on the control effect is greatly weakened, especially suitable for the control of nonlinear systems. Therefore, in the paper, the fuzzy controller is designed to adjust the five parameters of the fractional-order PID controller in real time.

The fuzzy controller has two input variables and five output variables. These two input variables are the vertical acceleration responses of the platform with MRE devices and its rate of change under the external disturbance signal. These five output variables are the correction values $(\Delta \lambda, \Delta \mu$, $\Delta k_{\mathrm{p}}, \Delta k_{\mathrm{i}}$, and $\left.\Delta k_{\mathrm{d}}\right)$ of the five parameters in the fractionalorder PID controller. The input and output variables all are discretized with seven grades: (NB (negative big), NM (negative medium), NS (negative small), ZO (zero), PS (positive small), PM (positive medium), and PB (positive big)\}. Their membership function curves are plotted in Figure 3. According to the fuzzy rules that should be followed when selecting the function, the characteristics of various membership functions, and the experience of experts, the membership functions of $\mathrm{A}$ (the difference between the vertical vibration acceleration and the set value) and $\mathrm{AC}$ (the rate of change) are selected as the combination of Gaussian function and linear triangle function. The membership functions of the five key parameters of fractional PID are selected as linear triangle functions. The five fuzzy rule tables corresponding to the five output variables $\left(\Delta \lambda, \Delta \mu, \Delta k_{\mathrm{p}}, \Delta k_{\mathrm{i}}\right.$, and $\left.\Delta k_{\mathrm{d}}\right)$ are Tables $1-5$.

\subsection{Optimal Fuzzy Fractional-Order PID Control Algorithm.} In this paper, the optimal fuzzy fractional-order PID (OFFO-PID) control algorithm is proposed to realize the vibration isolation and mitigation control of the precision platform with MRE devices. In the algorithm, the particle swarm optimization algorithm is used to get optimal initial values of five parameters of the fractional-order PID controller; according to the vertical acceleration responses of the platform with MRE devices and its rate of change under the external disturbance signal, the fuzzy controller is used to update five parameters of the fractional-order PID controller 
Table 1: Fuzzy rules of $\Delta \lambda$.

\begin{tabular}{|c|c|c|c|c|c|c|c|}
\hline \multirow{2}{*}{ A } & \multicolumn{7}{|c|}{ AC } \\
\hline & NB & NM & NS & ZO & PS & $\mathrm{PM}$ & $\mathrm{PB}$ \\
\hline NB & PB & PB & PM & MM & PS & PS & $\mathrm{ZO}$ \\
\hline NM & PB & $\mathrm{PB}$ & PM & PS & PS & $\mathrm{ZO}$ & NS \\
\hline NS & PM & $\mathrm{PM}$ & PM & PS & PS & $\mathrm{ZO}$ & NS \\
\hline $\mathrm{ZO}$ & PM & PM & PM & NM & $\mathrm{ZO}$ & NS & NS \\
\hline PS & PS & PS & $\mathrm{ZO}$ & NS & NS & NM & NM \\
\hline $\mathrm{PM}$ & PS & ZO & NS & NM & NM & NM & NB \\
\hline $\mathrm{PB}$ & $\mathrm{ZO}$ & $\mathrm{ZO}$ & NM & NM & NM & NB & NB \\
\hline
\end{tabular}

TABle 2: Fuzzy rules of $\Delta \mu$.

\begin{tabular}{|c|c|c|c|c|c|c|c|}
\hline \multirow{2}{*}{ A } & \multicolumn{7}{|c|}{ AC } \\
\hline & NB & NM & NS & $\mathrm{zO}$ & PS & PM & $\mathrm{PB}$ \\
\hline NB & NB & NB & NM & $\mathrm{PM}$ & NS & $\mathrm{ZO}$ & $\mathrm{ZO}$ \\
\hline NM & NB & NB & NM & NS & $\mathrm{ZO}$ & $\mathrm{ZO}$ & NS \\
\hline NS & NM & NS & NM & NS & $\mathrm{ZO}$ & PS & PS \\
\hline $\mathrm{ZO}$ & NM & NM & NS & $\mathrm{ZO}$ & PS & $\mathrm{PM}$ & $\mathrm{PM}$ \\
\hline PS & NM & NS & $\mathrm{ZO}$ & PS & PS & $\mathrm{PM}$ & PB \\
\hline $\mathrm{PM}$ & $\mathrm{ZO}$ & $\mathrm{ZO}$ & PS & PS & $\mathrm{PM}$ & PB & $\mathrm{PB}$ \\
\hline $\mathrm{PB}$ & $\mathrm{ZO}$ & $\mathrm{ZO}$ & PS & PM & PM & $\mathrm{PB}$ & $\mathrm{PB}$ \\
\hline
\end{tabular}

TABLE 3: Fuzzy rules of $\Delta k_{\mathrm{p}}$.

\begin{tabular}{|c|c|c|c|c|c|c|c|}
\hline \multirow{2}{*}{ A } & \multicolumn{7}{|c|}{ AC } \\
\hline & NB & $\mathrm{NM}$ & NS & $\mathrm{ZO}$ & PS & PM & PB \\
\hline NB & PB & PB & PM & PM & PS & $\mathrm{ZO}$ & $\mathrm{ZO}$ \\
\hline NM & $\mathrm{PB}$ & $\mathrm{PB}$ & PM & PS & PS & $\mathrm{ZO}$ & NS \\
\hline NS & PM & PM & PM & PS & PS & ZO & NS \\
\hline $\mathrm{ZO}$ & PM & PM & PM & PS & $\mathrm{ZO}$ & NS & NS \\
\hline PS & PS & PS & $\mathrm{ZO}$ & NS & NS & NM & NM \\
\hline PM & PS & $\mathrm{ZO}$ & NS & NM & NM & NM & NB \\
\hline $\mathrm{PB}$ & $\mathrm{ZO}$ & $\mathrm{ZO}$ & NB & NS & NM & NB & NB \\
\hline
\end{tabular}

TABLE 4: Fuzzy rules of $\Delta k_{\mathrm{i}}$.

\begin{tabular}{|c|c|c|c|c|c|c|c|}
\hline \multirow{2}{*}{ A } & \multicolumn{7}{|c|}{ AC } \\
\hline & NB & NM & NS & ZO & PS & PM & $\mathrm{PB}$ \\
\hline NB & NB & NB & NM & PM & NS & $\mathrm{ZO}$ & $\mathrm{ZO}$ \\
\hline NM & NB & NB & NM & NS & $\mathrm{ZO}$ & $\mathrm{ZO}$ & NS \\
\hline NS & NM & NS & NS & NS & $\mathrm{ZO}$ & PS & PS \\
\hline $\mathrm{ZO}$ & NM & NM & NS & ZO & PS & $\mathrm{PM}$ & $\mathrm{PM}$ \\
\hline PS & NM & NS & $\mathrm{ZO}$ & PS & PS & PM & $\mathrm{PB}$ \\
\hline PM & $\mathrm{ZO}$ & $\mathrm{ZO}$ & PS & PS & $\mathrm{PM}$ & $\mathrm{PB}$ & $\mathrm{PB}$ \\
\hline $\mathrm{PB}$ & $\mathrm{ZO}$ & $\mathrm{ZO}$ & PS & $\mathrm{PM}$ & $\mathrm{PM}$ & $\mathrm{PB}$ & PB \\
\hline
\end{tabular}

TABle 5: Fuzzy rules of $\Delta k_{\mathrm{d}}$.

\begin{tabular}{|c|c|c|c|c|c|c|c|}
\hline \multirow{2}{*}{ A } & \multicolumn{7}{|c|}{ AC } \\
\hline & NB & NM & NS & $\mathrm{ZO}$ & PS & PM & $\mathrm{PB}$ \\
\hline NB & PS & NS & NB & NB & NB & NM & PS \\
\hline NM & PS & NS & NB & NM & $\mathrm{NM}$ & NS & $\mathrm{ZO}$ \\
\hline NS & $\mathrm{ZO}$ & NS & NM & NM & NS & NS & $\mathrm{ZO}$ \\
\hline $\mathrm{ZO}$ & $\mathrm{ZO}$ & NS & NM & NM & NS & NS & $\mathrm{ZO}$ \\
\hline PS & $\mathrm{ZO}$ & $\mathrm{ZO}$ & $\mathrm{ZO}$ & $\mathrm{ZO}$ & $\mathrm{ZO}$ & $\mathrm{ZO}$ & $\mathrm{ZO}$ \\
\hline PM & $\mathrm{PB}$ & NS & PS & PS & PS & PS & $\mathrm{PB}$ \\
\hline $\mathrm{PB}$ & $\mathrm{PB}$ & PM & PM & PM & PS & PS & $\mathrm{PB}$ \\
\hline
\end{tabular}




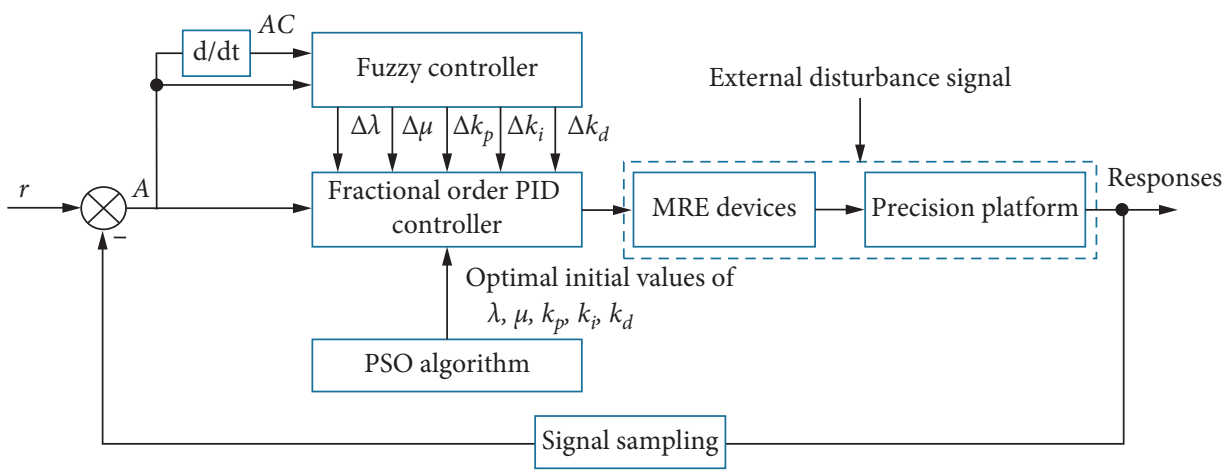

FIGURE 4: The control schematic diagram of the precision platform with the MRE device.

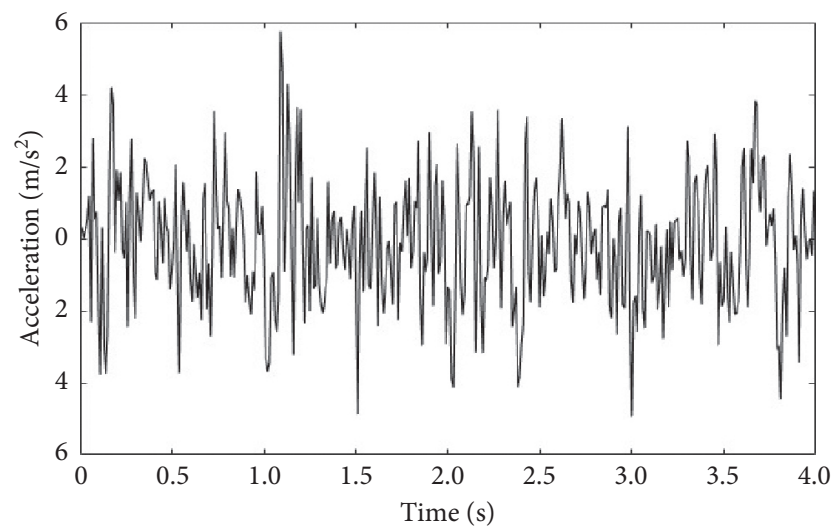

Figure 5: The external disturbance acceleration signal.

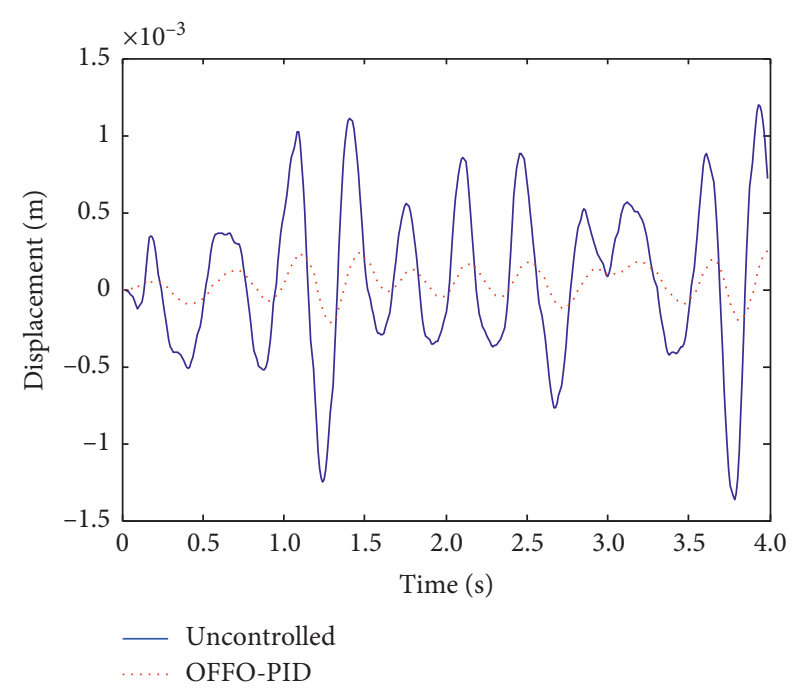

(a)

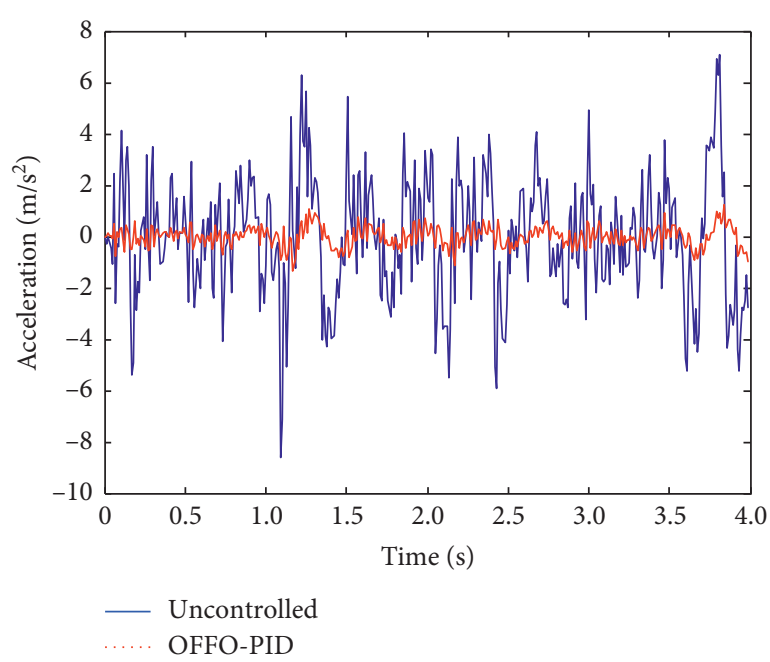

(b)

FIgURE 6: Vibration response comparison between the OFFO-PID control system and the uncontrolled system. (a) The displacement responses. (b) The acceleration responses.

in real time; and then the fractional-order PID controller is used to produce the control force of the precision platform with MRE devices. The control schematic diagram of the precision platform with the MRE device is shown in
Figure 4. It can be seen from the control schematic diagram that the correction values of the five control parameters of the fractional-order PID controller are obtained through calculation by the fuzzy controller, and the five variables of 


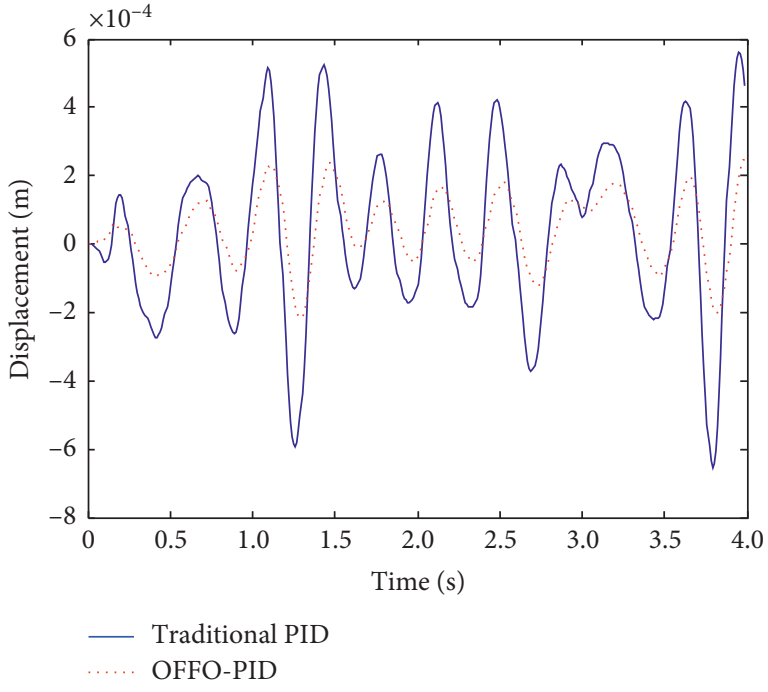

(a)

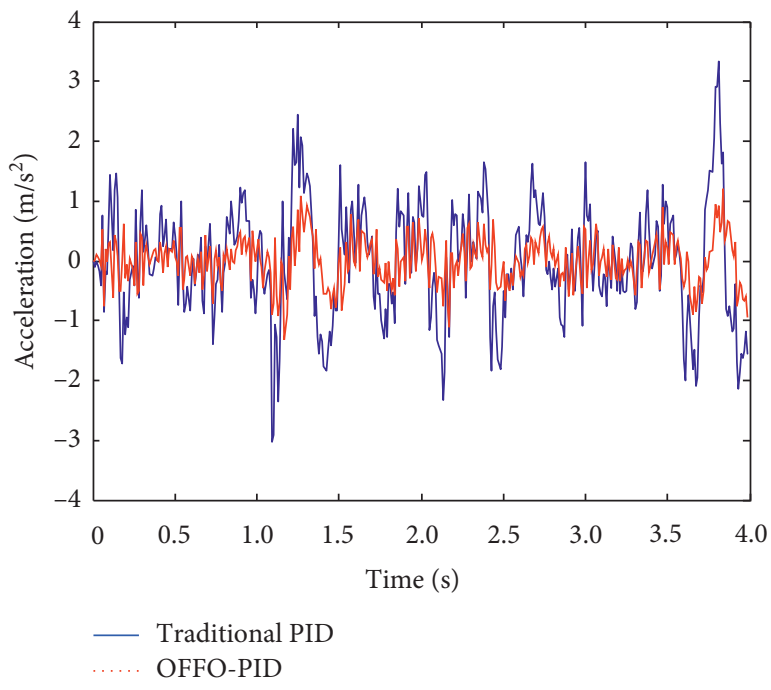

(b)

FIGURE 7: Vibration response comparison between the OFFO-PID control system and the traditional PID control system. (a) The displacement responses. (b) The acceleration responses.

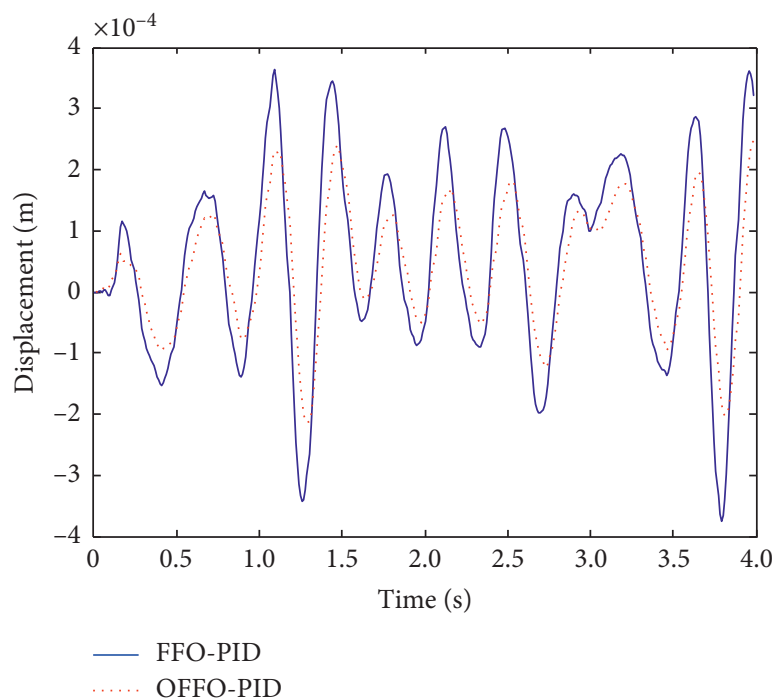

(a)

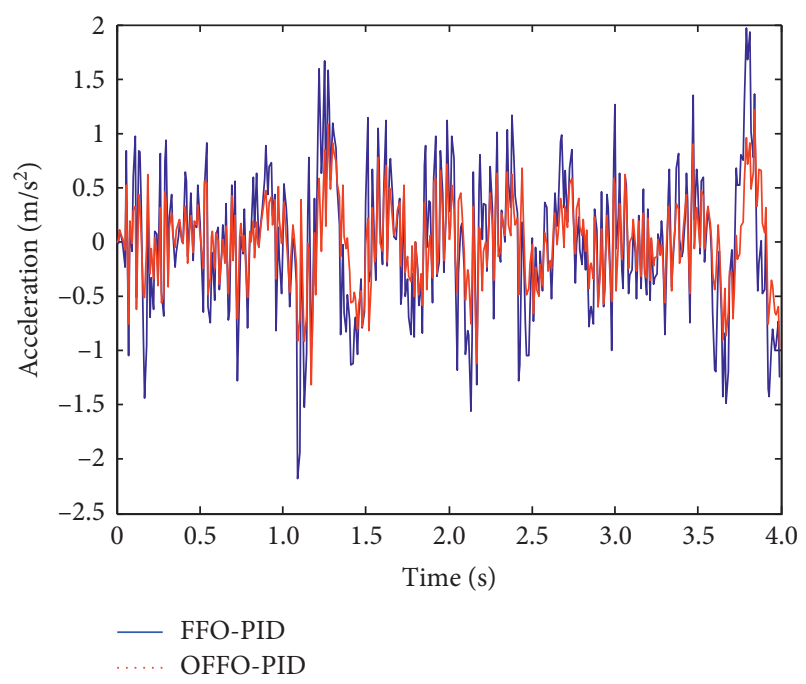

(b)

FIgURE 8: Vibration response comparison between the OFFO-PID control system and the FFO-PID control system. (a) The displacement responses. (b) The acceleration responses.

the fractional-order PID are tuned in combination with the particle swarm optimization algorithm. Finally, the fractional-order PID controller outputs the control current to the MRE devices. Among them, real-time adjustment of some parameters in the fractional-order PID controller is realized; thereby, real-time control of the system is realized.

\section{Dynamic Simulation Analysis}

In order to verify the effectiveness of the OFFO-PID control algorithm, the dynamic simulation of the entire control system of the precision platform is carried out. The parameters of the single degree-of-freedom model (in Figure 2) for the precision platform with the MRE devices are as follows: $m=600 \mathrm{~kg}, k_{0}=4122 \mathrm{kN} / \mathrm{m}, c_{0}=42.64 \mathrm{~N} \cdot \mathrm{s} / \mathrm{m}$, $A=0.0515 \mathrm{~m}^{2}$, and $t_{k}=10 \mathrm{~mm}$. Parameters of the designed PSO algorithm are the population size $N=100$, the maximum number of iterations $T=100$, the acceleration constants $c_{1}=c_{2}=2$, and the inertia factor $\omega$ decreases from 0.9 to 0.3 with the increase of iteration times. According to the traditional method, the parameters of the traditional PID controller are $k_{\mathrm{p}}=40.34, k_{\mathrm{i}}=30.65$, and $k_{\mathrm{d}}=13.34$; the parameters of the fractional PID controller based on the expert experience but not optimized by PSO algorithm are 
TABle 6: The maximum response comparison under different control methods.

\begin{tabular}{lcccc}
\hline & Uncontrolled & $\begin{array}{c}\text { Traditional } \\
\text { PID }\end{array}$ & $\begin{array}{c}\text { FFO- } \\
\text { PID }\end{array}$ & $\begin{array}{c}\text { OFFO- } \\
\text { PID }\end{array}$ \\
\hline $\begin{array}{l}\text { Displacement } \\
(\mathrm{mm})\end{array}$ & 1.366 & 0.6558 & 0.3728 & 0.2488 \\
$\begin{array}{l}\text { Acceleration } \\
\left(\mathrm{m} / \mathrm{s}^{2}\right)\end{array}$ & 8.607 & 3.367 & 2.664 & 1.455 \\
\hline
\end{tabular}

TABLE 7: Reduction rate of the OFFO-PID algorithm compared with other control methods (\%).

\begin{tabular}{lccc}
\hline & Uncontrolled & Traditional PID & FFO-PID \\
\hline Displacement & $81.78 \%$ & $62.06 \%$ & $33.26 \%$ \\
Acceleration & $83.09 \%$ & $56.78 \%$ & $45.38 \%$ \\
\hline
\end{tabular}

$k_{p}=75.52, k_{\mathrm{i}}=23.36, k_{\mathrm{d}}=50.57, \lambda=0.34$, and $\mu=0.13$; and the parameters of the fractional PID controller optimized by PSO are $k_{\mathrm{p}}=43.78, k_{\mathrm{i}}=12.37, k_{\mathrm{d}}=37.27$, $\lambda=0.57$, and $\mu=0.31$. The external disturbance acceleration signal is shown in Figure 5, and the time interval is $0.01 \mathrm{~s}$.

The dynamic simulation analysis of the entire precision platform system under different control methods is carried out by using MATLAB. Simulation results of the OFFO-PID control system are compared with those of the fuzzy fractional-order PID (FFO-PID, the parameters of the fractional PID controller are obtained from the expert experience rather than optimized using the PSO algorithm.) control system, the traditional PID control system, and the uncontrolled system. Figure 6 shows the displacement response and acceleration response comparison between the OFFOPID control system and the uncontrolled system. Figure 7 shows the displacement response and acceleration response comparison between the OFFO-PID control system and the traditional PID control system. Figure 8 shows the displacement response and acceleration response comparison between the OFFO-PID control system and the FFO-PID control system. Table 6 lists the maximum displacement and acceleration responses of the precision platform system under different control methods. Also, Table 7 lists reduction rate of the OFFO-PID algorithm compared with other control methods.

It can be seen from Figures 6-8 and Tables 6 and 7 that both displacement responses and acceleration responses of the OFFO-PID control system are effectively reduced compared with those of the uncontrolled system, the traditional PID control system, and the FFO-PID control system. The maximum displacement response of the OFFOPID control system is $0.249 \mathrm{~mm}$. Compared with the maximum displacement response of the uncontrolled system, $1.366 \mathrm{~mm}$, it is reduced by $81.77 \%$. Compared with the maximum displacement response of the traditional PID control system, $0.656 \mathrm{~mm}$, it is reduced by $62.06 \%$. And compared with the maximum displacement response of the FFO-PID control system, $0.373 \mathrm{~mm}$, it is reduced by $33.26 \%$. The maximum acceleration response of the OFFO-PID control system is $1.455 \mathrm{~m} / \mathrm{s}^{2}$. Compared with the maximum acceleration response of the uncontrolled system, $8.607 \mathrm{~m} /$ $\mathrm{s}^{2}$, it is reduced by $83.09 \%$. Compared with that of the traditional PID control system, $3.367 \mathrm{~m} / \mathrm{s}^{2}$, it is reduced by $56.78 \%$. And compared with the maximum acceleration response of the FFO-PID control system, $2.664 \mathrm{~m} / \mathrm{s}^{2}$, it is reduced by $45.38 \%$.

The comparison analysis shows that the fuzzy fractionalorder PID controller based on particle swarm optimization can effectively suppress the vibration response of the precision platform under certain vibration disturbance, and the simulation results show that it is obviously superior to the uncontrolled, nonoptimal, and traditional PID control.

\section{Conclusions}

In this paper, an optimal fuzzy fractional-order PID (OFFOPID) control algorithm is proposed to realize the vibration isolation and mitigation control of the precision platform with MRE devices. In the algorithm, the particle swarm optimization algorithm is used to get optimal initial values of five parameters of the fractional-order PID controller, the fuzzy control algorithm is used to update five parameters of the fractional-order PID controller in real time, and then the fractional-order PID controller is used to generate the control currents of MRE devices. In order to validate the effectiveness of the OFFO-PID control algorithm, dynamic simulation analysis for a platform with the MRE devices is carried out. Simulation results of the OFFO-PID control system are compared with those of the fuzzy fractional-order PID control system, the traditional PID control system, and the uncontrolled system. Analysis results show that the OFFO-PID control algorithm can effectively reduce the dynamic responses of the precision platform system, and the simulation results show that it is obviously superior to three other control methods.

\section{Data Availability}

The data used to support the findings of this study are included within the article.

\section{Conflicts of Interest}

The authors have no conflicts of interest.

\section{Acknowledgments}

This research was sponsored by the National Natural Science Foundation of China with Grant number 51878355, and it was gratefully acknowledged.

\section{References}

[1] Z.-D. Xu, X.-H. Huang, F.-H. Xu, and J. Yuan, "Parameters optimization of vibration isolation and mitigation system for precision platforms using non-dominated sorting genetic algorithm," Mechanical Systems and Signal Processing, vol. 128, pp. 191-201, 2019.

[2] M. Zaborski and M. Masłowski, "Magnetorheological elastomer composites," Trends in Colloid and Interface Science XXIV, vol. 138, pp. 21-25, 2011. 
[3] J.-T. Zhu, Z.-D. Xu, and Y.-Q. Guo, "Experimental and modeling study on magnetorheological elastomers with different matrices," Journal of Materials in Civil Engineering, vol. 25, no. 11, pp. 1762-1771, 2013.

[4] Z.-D. Xu, S. Suo, and Y. Lu, "Vibration control of platform structures with magnetorheological elastomer isolators based on an improved SAVS law," Smart Materials and Structures, vol. 25, no. 6, 2016.

[5] X. L. Gong, Y. Wang, T. Hu, and S. H. Xuan, "Mechanical property and conductivity of a flax fiber weave strengthened magnetorheological elastomer," Smart Materials and Structures, vol. 26, no. 7, 2017.

[6] J. D. Carlson and M. R. M. R. Jolly, "Fluid foam and elastomer devices," Mechatronics, vol. 10, no. 45, pp. 555-569, 2000.

[7] J. M. Ginder, W. F. Schloter, and M. E. Nichols, "Magnetorheological elastomers in tunable vibration absorbers," Proceedings of SPIE-The International Society for Optical Engineering, vol. 4331, pp. 103-110, 2001.

[8] Y. Yu, Y. Li, and J. Li, "Parameter identification of a novel strain stiffening model for magnetorheological elastomer base isolator utilizing enhanced particle swarm optimization," Journal of Intelligent Material Systems and Structures, vol. 26, no. 18, pp. 2446-2462, 2015.

[9] Y. Yu, J. C. Li, Y. C. Li, S. Q. Li, H. Li, and W. Q. Wang, "Comparative investigation of phenomenological modeling for hysteresis responses of magnetorheological elastomer devices," International Journal of Molecular Sciences, vol. 20, no. 13, p. 3216, 2019.

[10] Y. Yu, Y. C. Li, J. C. Li, and X. Y. Gu, "A hysteresis model for dynamic behavior of magnetorheological elastomer base isolator," Smart Materials and Structures, vol. 25, 2016.

[11] S. J. Dyke, B. F. Spencer, M. K. Sain, and J. D. Carlson, "Modeling and control of magnetorheological dampers for seismic response reduction," Smart Materials and Structures, vol. 5, no. 5, pp. 565-575, 1996.

[12] K. C. Schurter and P. N. Roschke, "Neuro-fuzzy control of structures using magnetorheological dampers," in Proceedings of the American Control Conference, IEEE, pp. 1097-1102, Arlington, VA, USA, June 2001.

[13] Z.-D. Xu, Y.-P. Shen, and Y.-Q. Guo, "Semi-active control of structures incorporated with magnetorheological dampers using neural networks," Smart Materials and Structures, vol. 12, no. 1, pp. 80-87, 2003.

[14] D. H. Wang and W. H. Liao, "Modeling and control of magnetorheological fluid dampers using neural networks," Smart Materials and Structures, vol. 14, no. 1, pp. 111-126, 2005.

[15] Y.-Q. Guo, S.-M. Fei, and Z.-D. Xu, "Simulation analysis on intelligent structures with magnetorheological dampers," Journal of Intelligent Material Systems and Structures, vol. 19, no. 6, pp. 715-726, 2008.

[16] C. M. D. Wilson and M. M. Abdullah, "Structural vibration reduction using self-tuning fuzzy control of magnetorheological dampers," Bulletin of Earthquake Engineering, vol. 8, no. 4, pp. 1037-1054, 2010.

[17] Y. Yu, Y. Li, and J. Li, "Nonparametric modeling of magnetorheological elastomer base isolator based on artificial neural network optimized by ant colony algorithm," Journal of Intelligent Material Systems and Structures, vol. 26, no. 14, pp. 1789-1798, 2015.

[18] Y. Yu, Y. C. Li, and J. C. Li, "Forecasting hysteresis behaviors of magnetorheological elastomer base isolator utilizing a hybrid model based on support vector regression and improved particle swarm optimization," Smart Materials and Structures, vol. 24, 2015.

[19] Y. Yu, S. Royel, J. Li, Y. Li, and Q. Ha, "Magnetorheological elastomer base isolator for earthquake response mitigation on building structures: modeling and second-order sliding mode control," Earthquakes and Structures, vol. 11, no. 6, pp. 943-966, 2016.

[20] X. Gu, Y. Yu, J. Li, and Y. Li, "Semi-active control of magnetorheological elastomer base isolation system utilising learning-based inverse model," Journal of Sound and Vibration, vol. 406, pp. 346-362, 2017.

[21] Y. Yu, Y. Li, J. Li, X. Gu, and S. Royel, "Nonlinear characterization of the MRE isolator using binary-coded discrete CSO and ELM," International Journal of Structural Stability and Dynamics, vol. 18, no. 8, 2018.

[22] D. X. Leng, K. Xu, Y. Ma, G. J. Liu, and L. Y. Sun, "Modeling the behaviors of magnetorheological elastomer isolator in shear-compression mixed mode utilizing artificial neural network optimized by fuzzy algorithm (ANNOFA)," Smart Materials and Structures, vol. 27, no. 11, pp. 849-858, 2018.

[23] X. Gu, Y. Yu, Y. Li, J. Li, M. Askari, and B. Samali, "Experimental study of semi-active magnetorheological elastomer base isolation system using optimal neuro fuzzy logic control," Mechanical Systems and Signal Processing, vol. 119, pp. 380-398, 2019.

[24] Z. D. Xu, Y. X. Liao, T. Ge, and C. Xu, "Experimental and theoretical study on viscoelastic dampers with different matrix rubbers," Journal of Engineering Mechanics, ASCE, vol. 142, no. 8, 2016.

[25] Z. C. Li and Y. Gong, "Research on ferromagnetic hysteresis of a magnetorheological fluid damper," Frontiers in Materials, vol. 6, p. 111, 2019.

[26] Z. C. Li, Y. Gong, S. H. Li, and W. J. Wang, "Magnetic hysteresis compensation control of a magnetorheological damper," Frontiers in Materials, vol. 6, p. 299, 2019.

[27] I. Podlubny, "Fractional-order systems and PI/sup /spl lambda//D/sup /spl mu//-controllers," IEEE Transactions on Automatic Control, vol. 44, no. 1, pp. 208-214, 1999.

[28] Z. Gao and X. Liao, "Improved oustaloup approximation of fractional-order operators using adaptive chaotic particle swarm optimization," Journal of Systems Engineering and Electronics, vol. 23, no. 1, pp. 145-153, 2012.

[29] R. C. Eberhart and Y. Shi, "Particle swarm optimization: Developments, applications and resources," in Proceeding Congress on Evolutionary Computation, IEEE Service Center, Seoul, Republic of Korea, May 2001.

[30] P. Indranil, D. Saptarshi, and G. Amitava, "Tuning of an optimal fuzzy PID controller with stochastic algorithms for networked control systems with random time delay," ISA Transactions, vol. 50, no. 1, pp. 28-36, 2011. 